\title{
Interpretations on how the macroscopic mechanical behavior of sandstone affected by microscopic properties-Revealed by bonded-particle model
}

\author{
Yo-Ming Hsieh ${ }^{\text {a }}$, Hung-Hui Li ${ }^{\mathrm{b}}$, Tsan-Hwei Huang ${ }^{\mathrm{b}}$, Fu-Shu Jeng ${ }^{\mathrm{b}, *}$ \\ a Department of Construction Engineering, National Taiwan University of Science and Technology, Taipei, Taiwan \\ ${ }^{\mathrm{b}}$ Department of Civil Engineering, National Taiwan University, Taipei, Taiwan
}

\section{A R T I C L E I N F O}

\section{Article history:}

Received 30 August 2007

Received in revised form 8 January 2008

Accepted 23 January 2008

Available online 23 February 2008

\section{Keywords:}

Sandstone

Bonded-particle model

Grain

Matrix

Particle contacts

\begin{abstract}
A B S T R A C T
Macroscopic mechanical properties of sandstones, such as uniaxial compressive strength and Young's modulus were found to be significantly affected by their petrographic properties, e.g. the porosity $\boldsymbol{n}$ and the grain area ration GAR. The intricate relationship between the macroscopic properties of sandstones and their petrographic or microscopic properties necessitates further study in exploring how the microscopic properties influence the macroscopic mechanical behavior.

In this research, numerical analyses based on the bonded-particle model, the microscopic properties of which originated from the bonded strength and stiffness, were thus conducted as a systematic study aiming at unraveling these microscopic mechanisms. A series of tests was conducted, and the results were compared with the actual behavior of sandstone. A numerical model comprised of three types of particles, grain particles $\mathbf{G P}$, matrix particles $\mathbf{M P}$ and porous matrix particles $\boldsymbol{P P}$, was accordingly proposed to represent the sandstone. The results of analyses demonstrated how the petrographic parameter $\boldsymbol{G A R}$ and porosity $\boldsymbol{n}$ determined the proportions and the numbers of $\mathbf{G P}, \mathbf{M P}$ and $\boldsymbol{P P}$. The strength and stiffness of these bonds were estimated based on back analyses. Accordingly, the results of parametric study indicate that matrix particles tend to have stronger bonding strength yet softer stiffness, when compared to the grain particles.
\end{abstract}

(c) 2008 Elsevier B.V. All rights reserved.

\section{Introduction}

Sandstone is a detrital sedimentary rock composed of rock fragments and mineral grains. The macroscopic mechanical behavior of sandstones, the uniaxial compressive strength (UCS) (ISRM, 1981) for instance, is inherently affected by the microscopic properties of the sandstone, e.g. the mineral types, porosity, bonding strength, etc. of the constituting particles. How do these microscopic properties of sandstones affect the macroscopic mechanical behavior of these rocks had been focus of interests in a number of recent researches. The influence of microscopic factors on the macroscopic strength of rock, were studied by various researchers with regard to the following aspects:

a) Mineralogical composition-The quartz content may contribute positively to the uniaxial compressive strength of sandstones (Smart et al., 1982; Gunsallus and Kulhaway, 1984; Shakoor and Bonelli, 1991). Nevertheless, there are situations that the quartz content of sandstones has no effect on their strength (Bell, 1978; Barbour et al., 1979; Dobereiner and De Freitas, 1986).

b) Cement and matrix-The strengths of sandstones are closely related to their cementation. Sandstones with higher cement content tend to have higher strength than those with lower cement content (Clough et al., 1981; David et al., 1998). The type of cement also

\footnotetext{
* Corresponding author. Tel.: +886 22363 0530; fax: +886 223645734 . E-mail address: fsjeng@ntu.edu.tw (F.-S. Jeng).
}

affects the sandstones' strength. For instance, sandstones with silica or calcareous cement have higher strength than the ones with clay mineral cement (Vutukuri et al., 1974). The term "matrix" is often referred to the fine particles between the grains. In sedimentology, these fine particles in fact include "matrix" deposited during sediment processes and "matrix" formed during diagenetic processes. In practice, especially when observing thin sections, it is difficult to distinguish the cement content within the fine particles. Hereinafter, the term "matrix" used in this work refers to the mixture of fine particles including both matrix and cement. As such, the matrix may exhibit bonding strength owing to the cement content within it.

c) Grain size-The effect of grain size on the strengths of sandstones may vary in accordance with the particular types of rocks studied. It has been found that increase in grain sizes results in decrease in uniaxial compressive strength for greywacke (Singh, 1988). While in other cases, there are no correlation between the grain size and the strength (Shakoor and Bonelli, 1991; Plachik, 1999).

d) Grain particle packing-The compactness of grain particle packing can be described by parameters such as the packing density, the grain contact, and the grain area ratio (GAR), which is defined as the ratio between the grain area and the total area in the selected range of the specimen image (Ersoy and Waller, 1995). Dobereiner and De Freitas (1986) suggested the strength of sandstones has no obvious correlation with the packing density, but positively correlates to the grain contact. Bell (1978) and Bell and Culshaw (1993), 
however, suggested higher packing density results in higher material strength.

Furthermore, other fundamental physical properties such as porosity, unit weight, and water content have been correlated to the uniaxial compressive strength of rocks (Dyke and Dobereiner, 1991; Hawkins and McConnell, 1992; Jeng et al., 1994; Hatzor and Plachik, 1997, 1998; Plachik, 1999; Jeng et al., 2002, 2004; Lin et al., 2005; Weng et al., 2005, 2008; Tsai et al., 2008). It was showed the strength decreases with increasing porosity and water content, and increases with increasing unit weight.

Jeng et al. (2004) and Weng et al. (2005) performed mechanical experiments and petrographic analyses on 13 different sandstone layers collected from the Western Foothill Range in Taiwan. The voids between particles can be either empty or partly filled with matrix materials. It has been found that fracture surfaces tend to go through particle-particle contacts or in between matrix when the sandstone is dry or wet, respectively (Lin et al., 2005).

In addition, since grains, matrix and porosity constitute the whole sandstone; how these entities affect the macro behavior is of interest. Through petrographic analysis, the influences of microscopic parameters (or petrographic parameters) on the macroscopic mechanical behaviors had been studied. Two parameters, the porosity $\boldsymbol{n}$ and the grain area ratio GAR were found to be the key parameters (Jeng et al., 2004). As a result, the uniaxial compressive strength (UCS) can be related to porosity $\boldsymbol{n}$ and $\mathbf{G A R}$ as shown in Eq. (1).

$\mathrm{UCS}=\left(133.7 \cdot e^{-0.107 n}\right)(3.2-0.026 \mathrm{GAR})$

Unit: MPa

Furthermore, the deformability (Young's modulus $\boldsymbol{E}$ ) was found to be related to porosity $\boldsymbol{n}$ and $\mathbf{G A R}$ as well (Jeng et al., 2004) and can be expressed as:

$\mathbf{E}=\left(36.3 \cdot e^{-0.106 n}\right)(0.354+0.017 \mathrm{GAR})$

Unit: GPa

From Eq. (2), it indicates that the Young's modulus of sandstones decreases with increasing porosity $\boldsymbol{n}$ and with decreasing $\boldsymbol{G A R}$. It should be noted that the porosity $\boldsymbol{n}$ typically ranges between $5 \%$ and $25 \%$, and $\boldsymbol{G A R}$ ranges between $20 \%$ and $75 \%$ for the studied sandstones. These two empirical equations, Eqs. (1) and (2), represent how the macroscopic strength and deformability of natural sandstones are related to porosity $\boldsymbol{n}$ and GAR. These empirical equations have been compared to sandstone worldwide (Bell and Culshaw, 1993, 1998; Ulusay et al., 1994) and were found to be consistent with the behavior of sandstones studied.

These two equations are adopted as the key relations to be met when validating and modifying numerical models and later analyses.

Some of the microscopic properties of rock can be directly measured or observed. For instance, the type of mineral and packing of grains can be measured from observing the thin sections of rocks under microscope. However, some other properties, e.g. the strength of matrix or the bonding strength of the grains, are difficult to measure directly. Moreover, in studying the influence of a particular microscopic factor, it would be ideal if the factor of interest could be varied while the other factors remained unchanged. Unfortunately, when natural rocks are used, frequently more than one factor will vary from specimen to specimen, rendering it difficult to evaluate, on identical bases, the unbiased influence of a particular factor.

There is very little study on the effect of matrix strength and stiffness on the macroscopic strength of rock. Despite these difficulties, a numerical model that is capable of accounting for the discrete packing nature of grains and the bonding strength, can serve as convenient means in studying the influence of microscopic properties on the macroscopic behavior of rock. Among the existing discrete numerical models, bonded-particle model (BPM) possesses the desirable requirements mentioned above, and this model was firstly tested and eventually adopted in this research. By using BPM, the bonding strength between the matrix and the grain can be systematically varied and the corresponding variation of macroscopic mechanical behavior can be observed. As a result, clarification on the effects of the matrix on mechanical behaviors of sandstones is accordingly obtained.

\section{Methodology-a modified bonded-particle model}

The framework of this study is illustrated in Fig. 1. Before adopting BPM for studying microscopic mechanisms, the numerical model must be tested and modified until it shows adequate macroscopic mechanical behavior. Therefore, as shown in Fig. 1, uniaxial compress tests were simulated and compared (Steps 1 and 2) and the results were verified (Verification I).

As such, the uniaxial compression was first modeled using BPM, and it was revised iteratively until it yields reasonable macroscopic uniaxial compression behavior (similar uniaxial compressive strength and Young's modulus). This test also serves the purpose of determining BPM's microscopic parameters. After the test, a 2-dimensional numerical model was found to be capable of yielding a reasonable macroscopic mechanical response and was thus adopted as the tool for further analyses.

\subsection{Setup of the modified BPM}

In this study, a bonded-particle model (Potyondy and Cundall, 2004), which enables assembly and bonding of discrete circle particles, is considered for simulating the aggregation and cementation of the sandstone. Intuitively, the bonded-particle model differs from the natural sandstone in the following aspects: (1) the grains of nature

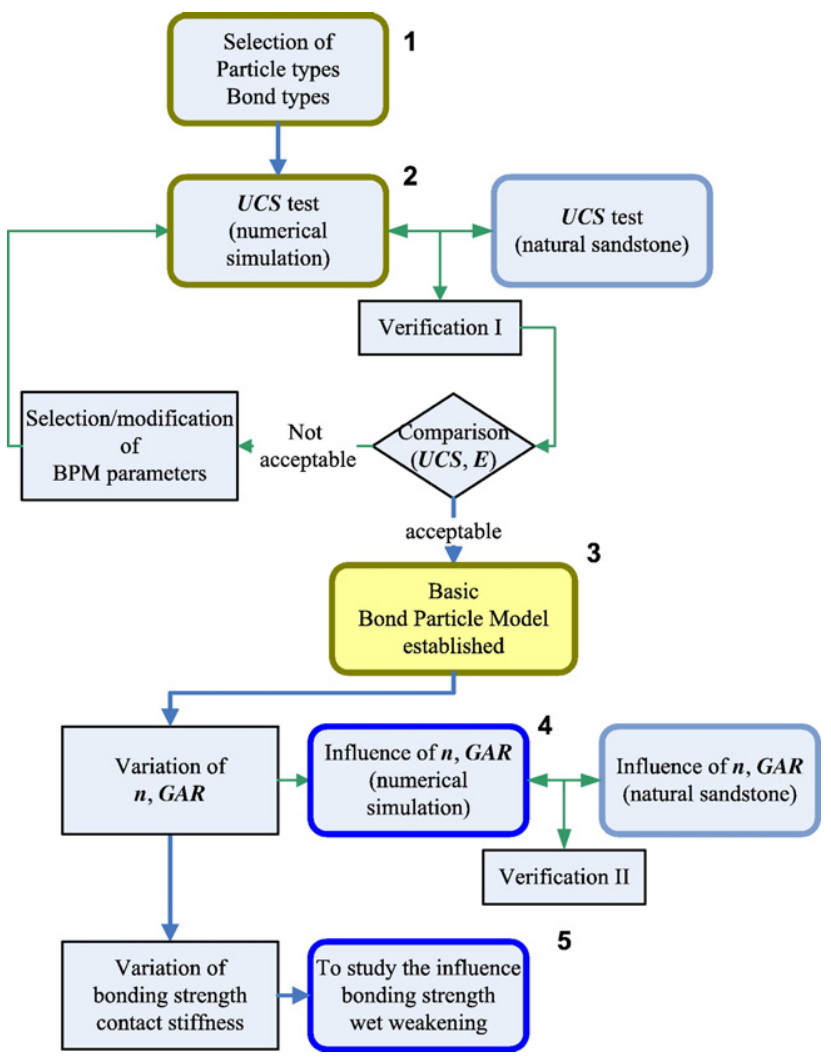

Fig. 1. Schematic illustration of the framework of this research. 


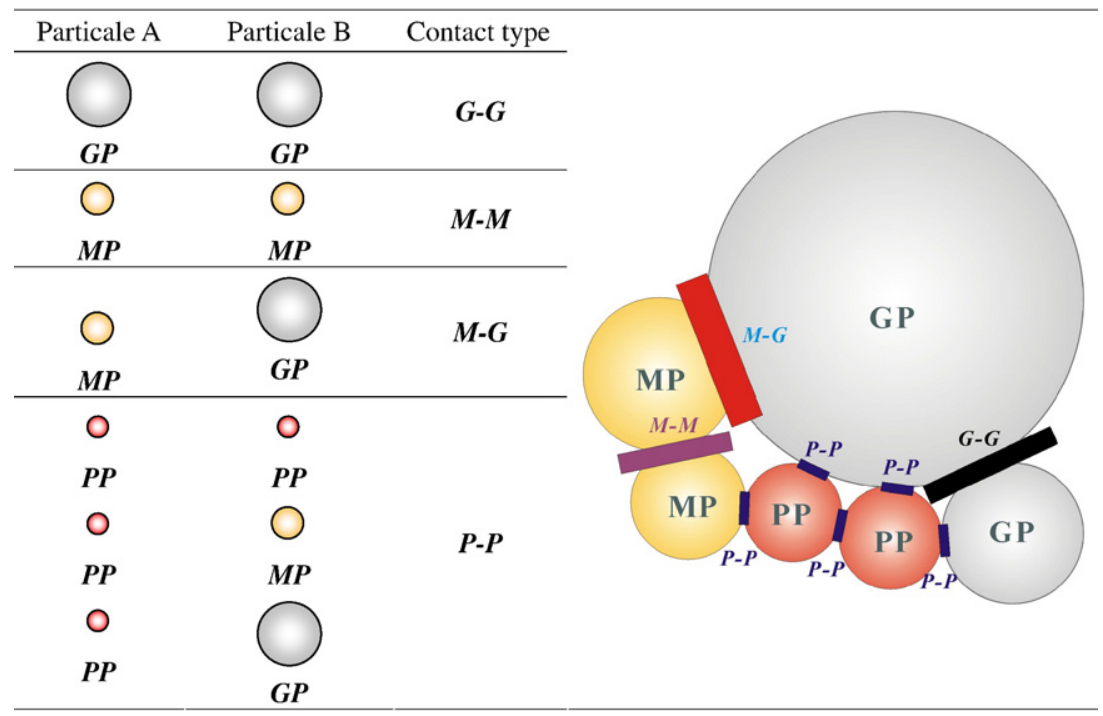

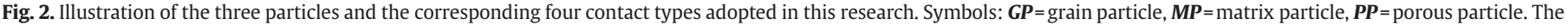
thick lines depict the width of the parallel bond between the particles.

sandstone are not necessarily spherical; (2) the contact of natural grains may often show "line-contact" as observed in thin sections; however, the contact of BPM is either "point contact" or a segment of line-contact in between two particles, the so-called "parallel bond", as shown in Figs. 2; and (3) the number of grains opted when conducting numerical analysis can be much less than the actual number of grains in the real rock. Therefore, it is necessary to test and perform necessary modifications on the BPM so that adequate mechanical behaviors can be reproduced by the numerical model.

Since the natural sandstone is composed of grains, matrix, cement and void, particles representing grains and matrix were accordingly introduced into the BPM. One of the major difficulties simulating natural sandstones is to model sandstone with high porosity. Natural sandstone typically shows porosity in the range of $10 \%-25 \%$; however, the use of BPM to model sandstone with large porosity may often result in "floating particles", i.e. some particles are not supported or in contact with other grains owing to the limited number of particles opted. If a wider range of grain size distribution, like natural sandstone may have, is used, it is expected that there would be much less or none floating particles in the model.

To overcome the aforementioned issue of floating particles in BPM, an additional type of particle representing the "porous matrix" was introduced. Therefore, this work allows modeling of high-porosity

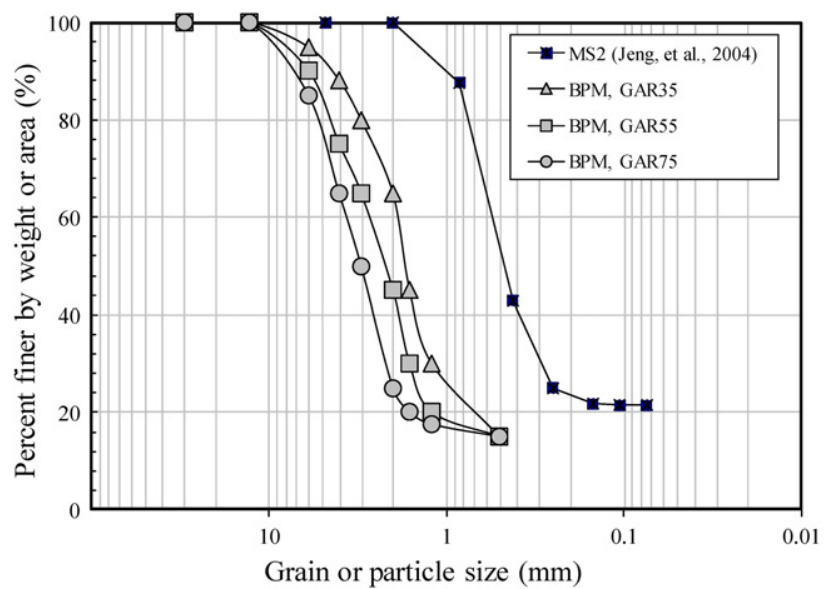

Fig. 3. Grain size distribution of the sandstone studied and the grain size distribution adopted. sandstones without leading to unsupported, floating particles. As a result, the proposed model contains three types of particles representing grain, matrix and porous matrix. These particle types are respectively denoted as $\mathbf{G P}, \boldsymbol{M P}$ and $\boldsymbol{P P}$. This modification enables controlled variation of the $\boldsymbol{G A R}$ and porosity $\boldsymbol{n}$ of the model while observing the macroscopic variation of $\boldsymbol{U C S}$ and Young's modulus $\boldsymbol{E}$.

Once the numerical procedure with desired control on both microscopic and index properties is validated, the mechanisms behind "wet softening" can then be studied. Some of the weak sandstones possess "wet softening" behavior, and were found to be related to $\boldsymbol{G A R}$ and porosity $\mathbf{n}$ as well as wet weakening of the matrix (Jeng et al., 2004; Lin et al., 2005). The modified BPM predicts macroscopic strength and deformability based on independent parameters including: (1) GAR and porosity; and (2) the strength and the deformability of the matrix particles and the porous matrix particles.

The three types of particles ( $\boldsymbol{G P}, \boldsymbol{M P}$ and $\boldsymbol{P P})$ in the proposed model resulted in six different types of bonds between these three particle types (Fig. 2). Since the porous matrix particle $\boldsymbol{P P}$ should be the weakest material among the three types of particles, the bonding strength of $\boldsymbol{P P}$ with other types of particles should be dominated by the weakest bonding strength of $\boldsymbol{P P}$. Therefore, the $\boldsymbol{P}-\boldsymbol{G}$ and $\boldsymbol{P}-\boldsymbol{M}$ bonds are replaced by $\boldsymbol{P}-\boldsymbol{P}$ bonds. As a result, a total of four types of bonds were used in the proposed model (Fig. 2).

\subsection{Properties of natural sandstone simulated}

The natural sandstone simulated is the one studied by Jeng et al. (2004), and its $\boldsymbol{U C S}$ and $\boldsymbol{E}$ of are summarized in Table 1. The grain size distribution of this natural sandstone was obtained by petrographic studies, as shown in Fig. 3 (Jeng et al., 2004). Particle sizes of the model were determined based on the natural size distribution. As shown in Fig. 3, the sizes of the particles in simulation are about 10 times greater

Table 1

Macroscopic properties of the sandstone studied and the simulated results yielded by the proposed numerical model

\begin{tabular}{lrr}
\hline Items & Value & Unit \\
\hline Natural sandstone studied & 39.6 & $\mathrm{MPa}$ \\
$\quad$ Uniaxial compressive strength $\boldsymbol{U C S}$ & 7.9 & $\mathrm{GPa}$ \\
Young's modulus $\boldsymbol{E}$ & & \\
Prediction of the proposed model & 41.6 & $\mathrm{MPa}$ \\
$\quad$ Uniaxial compressive strength $\boldsymbol{U C S}$ & 8.4 & $\mathrm{GPa}$ \\
Young's modulus $\boldsymbol{E}$ & &
\end{tabular}


than the actual grain size owing to the limitation of total number of particles limited by the available computing resource. The grain size distributions for various $\boldsymbol{G A R}$ are selected to be similar to the natural one, as shown in Fig. 3. The size of particles ranges between $0.5 \mathrm{~mm}$ and $6 \mathrm{~mm}$, and particles with diameter less than or equal to $2 \mathrm{~mm}$ are selected as matrix particle $\mathbf{M P}$.

The material-genesis procedures is summarized and illustrated in Fig. 4. Fig. 5a, b, and c shows the respective typical distributions of $\boldsymbol{P P}$, MP and GP particles based on the above-mentioned concepts. The particles were randomly distributed inside a specimen of $5.5 \mathrm{~cm}$ in width and $13 \mathrm{~cm}$ in height. Fig. 5d shows the complete model specimen with $\mathbf{G A R}=55 \%$ and $\boldsymbol{n}=25 \%$, and there are 8487 particles and 17,123 contact points in this numerical model. The numbers of $\mathbf{G}-\mathbf{G}$, $\boldsymbol{M - G}, \boldsymbol{M}-\boldsymbol{M}$ and $\boldsymbol{P}-\boldsymbol{P}$ contacts are 170, 1564, 1587 and 13,802, respectively. The number of particles and contact points varies with the variation of petrographic parameters, e.g. $\boldsymbol{G A R}$ and $\boldsymbol{n}$, and these parameters also affects the relative ratio of the four different types of contacts, as will be discussed in Section 4.

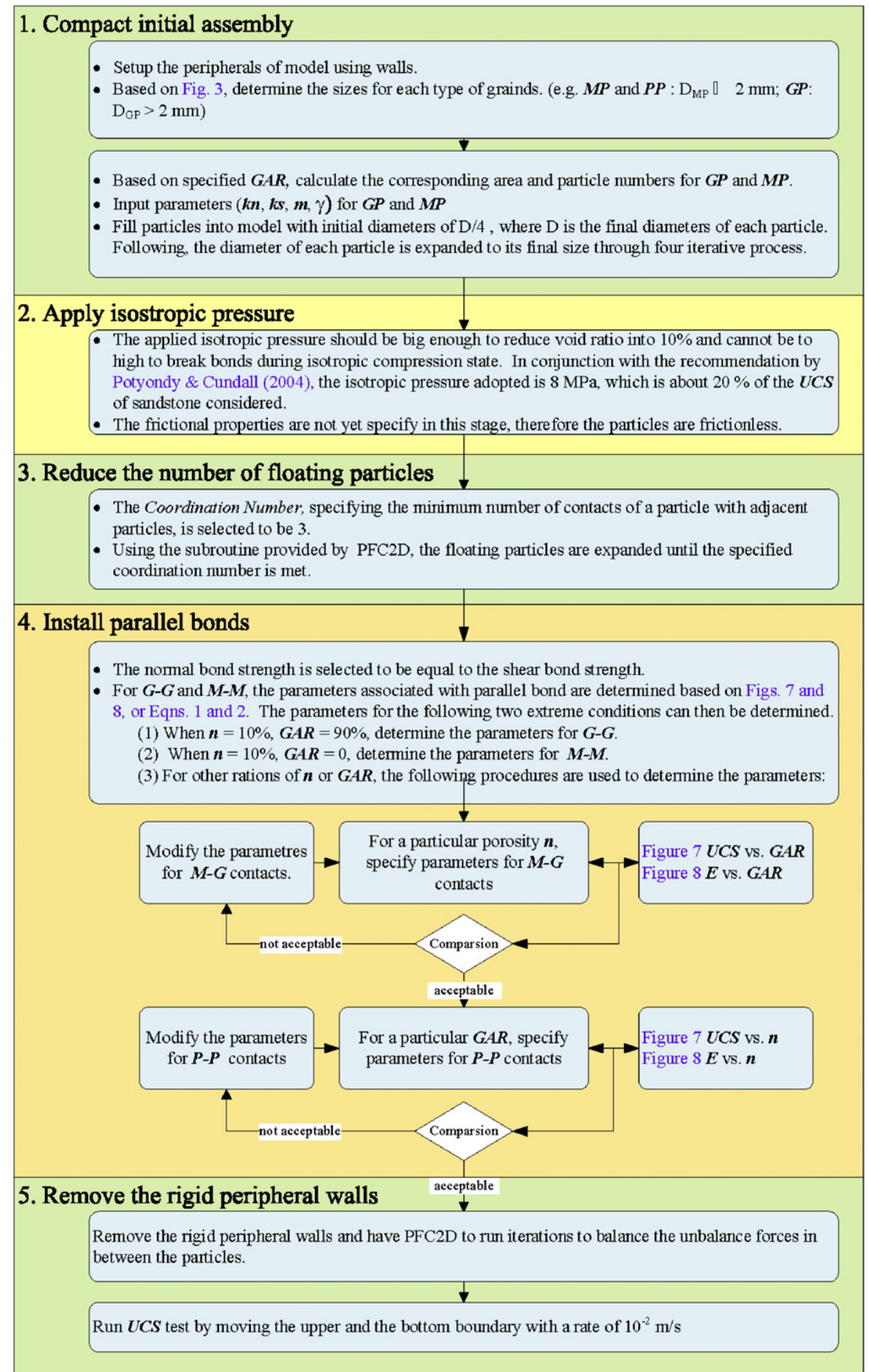

Fig. 4. Illustration of the material-genesis procedures. 


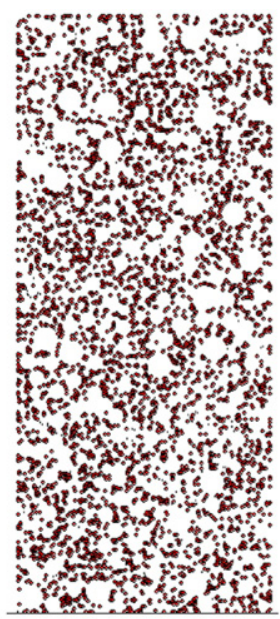

(a) Porous Matrix (15\%)

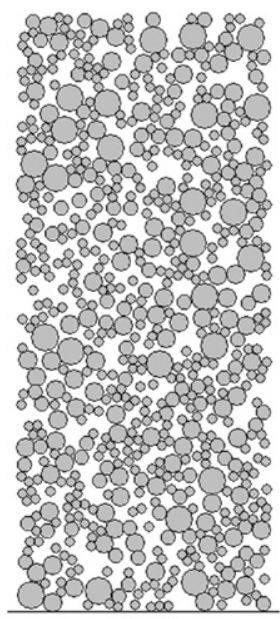

(c) Grain $(55 \%)$

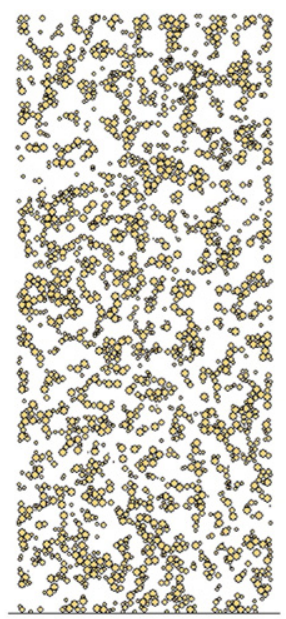

(b) Matrix (20\%)

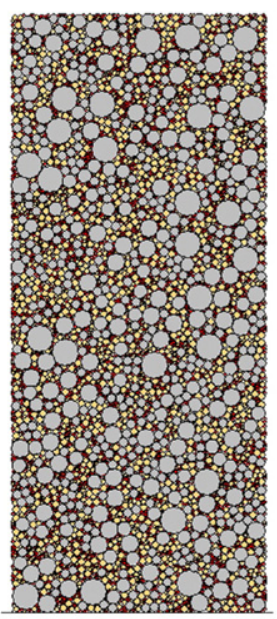

(d) Grain + Matrix + Porous Matrix

Fig. 5. Distribution of the grain, matrix and porous matrix particles of the proposed numerical model, with $\boldsymbol{n}=25 \%$ and $\boldsymbol{G A R}=55 \%$. The percentages of $\boldsymbol{G A R}$ and $\boldsymbol{n}$ are defined as the ratios of grain area and void area over the total area, respectively. The addition of the two ratios of void (10\%) and porous matrix (15\%) altogether is taken as porosity $\boldsymbol{n}$.

\subsection{Input parameters required}

The proposed modeling was carried out using PFC2D, which has the following features: (1) the particles are considered as homogenous rigid disks; (2) the interaction between particles is described as a soft contact, which occurs at the contact point between two particles; (3) the particles are allowed to slightly overlap each other at the contact points when subjected to compression; and (4) the slip condition between particles is governed by the Mohr-Coulomb friction (PFC2D, 2004). As a result, the microscopic parameters involved include:

(1) The stiffness of particle and parallel bond-the normal stiffness $k_{\mathrm{n}}$, shear stiffness $k_{\mathrm{s}}$, the parallel-bond normal stiffness $k_{\mathrm{np}}$ and the parallel-bond shear stiffness $k_{\mathrm{sp}}$;

(2) The surface friction coefficient $\mu$ between particles;

(3) The strength of bonding-the normal bonding strength $\sigma$, the shear bonding strength $\tau$; and

(4) The width of bonding-the parallel-bond radius multiplier $\lambda$.

(5) In this work, a parallel bond in between two particles was adopted to simulate the bonding behavior between particles. As shown in Fig. 2, parallel-bond model assumes that two particles are bonded by a rectangle block with a width of $2 \lambda \bar{R}=2 \lambda$ min $\left(R^{\mathrm{A}}, R^{\mathrm{B}}\right)$, in which the $\lambda$ is parallel-bond radius multiplier; $R^{\mathrm{A}}$,
$R^{\mathrm{B}}$ are radii of adjacent particles $\mathrm{A}$ and $\mathrm{B}$. Parallel bonds are capable of taking normal force, shear force and moment. When the normal stress or shear stress acting on the rectangle block exceeds the strength, the parallel bond fails and will be removed from the model.

\subsection{Simulation of uniaxial compression test}

To simulate uniaxial compressive tests, the upper and lower boundaries were selected to be frictionless rigid plates, and lateral boundaries were unconstrained. Gravity effect was not considered in this study, as the specimen was small, and the gravity-induced stress gradient had negligible effect on the macroscopic behavior. The unconfined uniaxial compression test was simulated by vertically moving both the upper and the lower plates toward the center of the specimen at a constant velocity of $10^{-2} \mathrm{~m} / \mathrm{s}$. This loading rate, confirmed in this study and by Iverson (2003), was the upper limit that the loading rate imposed little effects on the UCS.

Using the basic model shown in Fig. 5, the GAR can be increased by randomly changing some of the $\boldsymbol{M P}$ into $\boldsymbol{G P}$. Models were setup with $\boldsymbol{G A R}$ of 35\%,55\%, and 75\%. Similarly, the porosity $\boldsymbol{n}$ can be decreased by randomly changing some of $\boldsymbol{P P}$ into $\mathbf{M P}$, and the resultant porosity used in this study ranges from $10 \%$ to $25 \%$.

\subsection{Validation of the proposed numerical model-Verification I}

As shown in Fig. 1 (Step 2), the validity of the proposed model was first checked by simulating a series of uniaxial compression tests and by comparing with the experimental results from Jeng et al. (2004) and Weng et al. (2005), as shown in Fig. 6. During this process (Figs. 1 and 4), the simulated macroscopic deformational behavior and the strength were made consistent with natural ones by iteratively refining the microscopic model parameters. Until the resultant macroscopic behavior compares well with the natural ones (Fig. 1, Step 3), the corresponding parameters are then determined.

These parameters were determined by matching the calculated macroscopic strength (UCS) and stiffness (Young's modulus $\boldsymbol{E}$ ) with physically measured ones listed in Table 1 . The model parameters were determined based on curve-fitting method, and the values used in this study are listed in Tables 2 and 3.

Fig. 6 compares the stress-strain curves respectively obtained by experiment and by numerical simulation. It can be seen that these two curves shown in Fig. 6 are consistent in general and the peak strength is also similar. Similar to natural rocks and as shown in Fig. 6, the bonded-particle model fractures at peak strength, followed by substantial drop of resisting stress after peak; such behavior represents a typical brittle fracture. After the peak, a major, inclined fracture

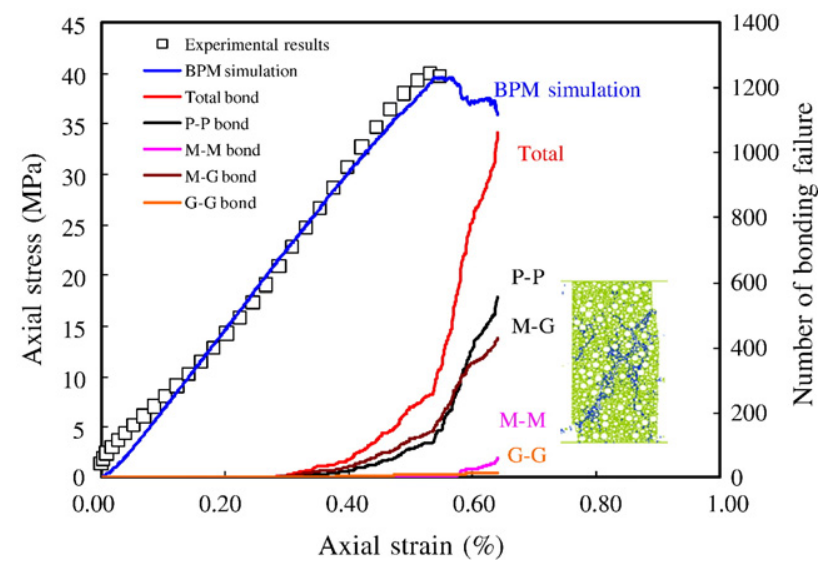

Fig. 6. Comparison of the experimental and simulated stress-strain curve when $\boldsymbol{n}=20 \%$ and $\mathbf{G A R}=35 \%$. 
Table 2

Microscopic properties of grain $(\boldsymbol{G P})$, matrix $(\boldsymbol{M P})$ and porous matrix particles $(\boldsymbol{P P})$

\begin{tabular}{lrrrl}
\hline Items & \multicolumn{1}{c}{$G P$} & \multicolumn{1}{c}{$M P$} & \multicolumn{1}{c}{$P P$} & Unit \\
\hline Particle density, $\rho$ & 2660.0 & 2660.0 & 2660.0 & $\mathrm{~kg} / \mathrm{m}^{3}$ \\
Young's modulus of particle & 47.9 & 8.9 & 7.1 & $\mathrm{GPa}$ \\
Particle normal/shear stiffness, $k_{\mathrm{n}} / k_{\mathrm{s}}$ & 2.4 & 2.4 & 2.4 & \\
Particle friction coefficient, $\mu$ & 0.5 & 0.5 & 0.5 &
\end{tabular}

Remarks: The parameters are determined based on the $\mathbf{G A R}=75 \%, \boldsymbol{n}=15 \%$ and adopted as the base case.

surface formed in the specimen upon subsequent loading, and eventually the original intact specimen is broken apart. This fracture pattern is also similar to the natural rock.

Accordingly, the set of parameters shown in Tables 2 and 3 was adopted as the base set of parameters used for further analysis. Since the strengths of shear and normal bonds were not actually measured, the values listed in Table 3 are obtained based on back analyses. The strength of normal and shear bonds have been evaluated and it was found that, as long as the rock tends to have brittle failure under uniaxial compression tests, the relative strength of shear to normal bonds has little influence on the UCS (Potyondy and Cundall, 2004; Cho et al., 2007). As such, the ratio of shear to normal bonding strength was selected to be one. Back analyses have been conducted to evaluate this ratio of strength of shear and normal bonds for sandstone in this research. The results indicate that: (1) UCS is controlled by normal bond and (2) the shear bond has little influence on the UCS. This result is similar to the results observed from granite. Therefore, the normal bonding strength was selected by best-fitting $\boldsymbol{U C S}^{\prime}$ and the shear bonding strength was selected to be identical to normal bond for convenience. However, it should be noted that the shear bonding strength selected in this research is not necessary the real or "representative" one.

Using BPM, it is possible to track the number of bonding failure between particles. Fig. 6 shows the number of failed parallel bonds in the course of a uniaxial compression test with $\boldsymbol{n}=20 \%$ and $\mathbf{G A R}=35 \%$. The initial bonding breakage started when the axial strain reached $50 \%$ of the yield strain (the strain corresponds to the peak strength), and the number of breakage significantly increased when the axial strain approached the yield strain. It was also observed that the breaking of $\boldsymbol{P}-\boldsymbol{P}$ and $\boldsymbol{M}-\boldsymbol{G}$ bonds outnumbered the breaking of $\boldsymbol{M}-\boldsymbol{M}$ and $\boldsymbol{G}-\boldsymbol{G}$ bonds, as shown in Fig. 6. The observation on the number as well as the type of bonding failure enables us to find the insights regarding the dominating failure mechanism of sandstones; this will be further discussed in Section 4.

\subsection{Further validation-Verification II}

The validity of the proposed model was then further tested, as shown in Figs. 1 and 4 (Step 4), by comparing the computed variation of $\boldsymbol{U C S}$ with $\boldsymbol{G A R}$ and porosity $\boldsymbol{n}$ to the natural ones such as the observed correlation shown by Eqs. (1) and (2) and Figs. 7 and 8 (Jeng et al., 2004). As will be discussed in later sections, the results of tests were found to be acceptable and the proposed model was thus adopted for further study of the sandstone.

Table 3

Parameters of parallel bonds for $\boldsymbol{G}-\boldsymbol{G}, \boldsymbol{M}-\boldsymbol{M}, \boldsymbol{M}-\boldsymbol{G}$ and $\boldsymbol{P}-\boldsymbol{P}$ contacts

\begin{tabular}{lrrrrll}
\hline Items & \multicolumn{3}{l}{ Contact types } & & \multirow{3}{*}{ Unit } \\
\cline { 2 - 5 } & $G-G$ & $M-M$ & $M-G$ & $P-P$ & \\
\hline Parallel bond radius multiplier, $\lambda$ & 1.0 & 1.0 & 1.0 & 0.08 & \\
Young's modulus of parallel bond & 47.9 & 8.9 & 7.5 & 7.1 & $\mathrm{GPa}$ \\
Normal/shear stiffness of parallel bond, $k_{\mathrm{np}} / k_{\mathrm{sp}}$ & 2.4 & 2.4 & 2.4 & 2.4 & \\
Normal strength of parallel bond & 35.8 & 143.7 & 50.0 & 143.7 & $\mathrm{MPa}$ \\
Shear strength of parallel bond & 35.8 & 143.7 & 50.0 & 143.7 & $\mathrm{MPa}$ \\
\hline
\end{tabular}

Remarks: The parameters are determined based on the $\mathbf{G A R}=75 \%, \boldsymbol{n}=15 \%$ and adopted as the base case.

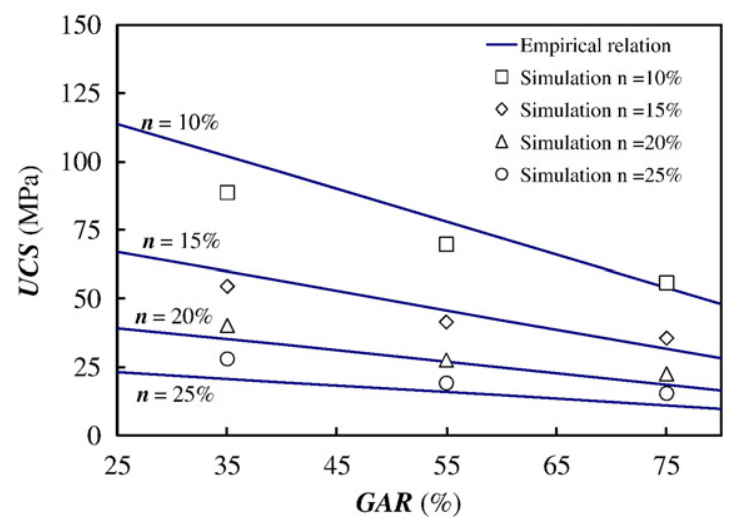

Fig. 7. Empirical relation of $\boldsymbol{U C S}$ with $\boldsymbol{G A R}$ and porosity $\boldsymbol{n}$. The simulated $\boldsymbol{U C S}$ ' are also plotted for comparison.

As long as the influence of petrographic factors on $\boldsymbol{U C S}$ and $\boldsymbol{E}$ obtained by empirical correlations can be simulated (Step 4 in Fig. 1), the base set of microscopic parameters is determined in the meantime, as the ones summarized in Tables 2 and 3. Parametric studies can then be performed to learn the influence of macroscopic properties, including bonding strengths in between different types of particles on the strength reduction owing to possible wet softening (Step 5 in Fig. 1).

\section{Influence of $G A R$ and $n$}

\subsection{Influence of GAR and $\boldsymbol{n}$ on $\mathbf{U C S}$}

Fig. 7 shows the variation of $\boldsymbol{U C S}$ with $\boldsymbol{G A R}$ and porosity $\boldsymbol{n}$ obtained from the proposed model and the comparison to the empirical correlations founded by Jeng et al. (2004). It can be seen that, for a given porosity $\boldsymbol{n}$, increasing GAR decreases the UCS. This observation, combined with the fact that increasing of $\boldsymbol{G A R}$ under a given porosity $\boldsymbol{n}$ reduces the matrix content, suggests the possibility that the bonding strength in between matrix particles $(\boldsymbol{M}-\boldsymbol{M})$ is greater than the bonding strength in between grain particles (G-G) (Jeng et al., 2004). On the other hand, under a particular $\boldsymbol{G A R}$, the decrease of porosity $\boldsymbol{n}$ leads to an increase in $\boldsymbol{U C S}$ as shown in Fig. 7. The increase of grains and matrix, i.e. the decrease of porosity $\boldsymbol{n}$, tends to better support the applied load and accounts for the increase of $\boldsymbol{U C S}$.

When compared to the behavior of actual sandstone, the abovementioned influence of GAR and porosity $\boldsymbol{n}$ on $\boldsymbol{U C S}$ is consistent with the empirical relations shown in Fig. 7, except that, at lower porosity (e.g., $\boldsymbol{n}=10 \%$ ), the empirical relation exhibits a somewhat greater range of variation upon varying $\mathbf{G A R}$.

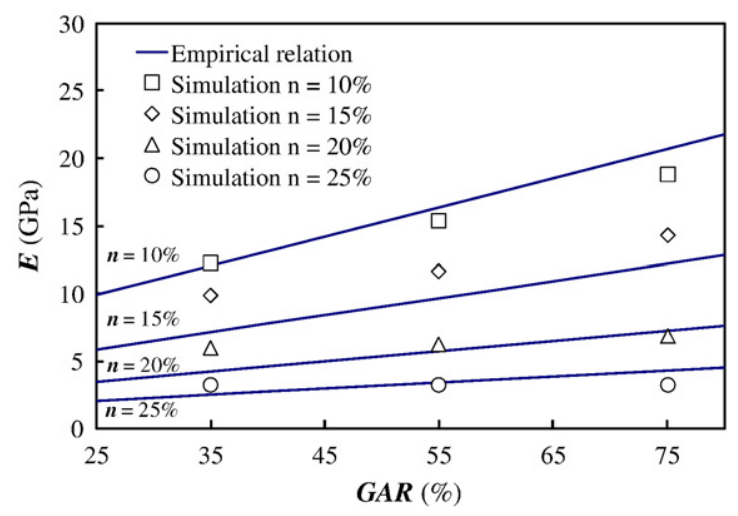

Fig. 8. Empirical relation of Young's modulus $\boldsymbol{E}$ with $\boldsymbol{G A R}$ and porosity $\boldsymbol{n}$. The simulated Es are also plotted for comparison. 
Table 4

Summation of the particle numbers, contact numbers and the relative contents of the adopted particles for the cases analyzed

\begin{tabular}{|c|c|c|c|c|c|c|c|c|}
\hline \multicolumn{2}{|c|}{ GAR (\%) } & $n(\%)$ & $\begin{array}{l}\text { Particle } \\
\text { number }\end{array}$ & $\begin{array}{l}\text { Contact } \\
\text { number }\end{array}$ & $\begin{array}{l}G-G \\
(\%)\end{array}$ & $\begin{array}{l}M-M \\
(\%)\end{array}$ & $\begin{array}{l}M-G \\
(\%)\end{array}$ & $\begin{array}{l}P-P \\
(\%)\end{array}$ \\
\hline \multirow[t]{4}{*}{$\overline{\text { (a) }}$} & \multirow[t]{4}{*}{35} & 10 & \multirow[t]{4}{*}{12,113} & \multirow[t]{4}{*}{23,856} & 0 & 82 & 18 & 0 \\
\hline & & 15 & & & 0 & 61 & 15 & 24 \\
\hline & & 20 & & & 0 & 43 & 12 & 45 \\
\hline & & 25 & & & 0 & 27 & 9 & 63 \\
\hline \multirow[t]{4}{*}{ (b) } & \multirow[t]{4}{*}{55} & 10 & \multirow[t]{4}{*}{8487} & \multirow[t]{4}{*}{17,123} & 1 & 66 & 33 & 0 \\
\hline & & 15 & & & 1 & 42 & 25 & 32 \\
\hline & & 20 & & & 1 & 23 & 17 & 59 \\
\hline & & 25 & & & 1 & 9 & 9 & 81 \\
\hline \multirow[t]{4}{*}{ (c) } & \multirow[t]{4}{*}{75} & 10 & \multirow[t]{4}{*}{7606} & \multirow[t]{4}{*}{15,328} & 2 & 51 & 47 & 0 \\
\hline & & 15 & & & 2 & 28 & 34 & 36 \\
\hline & & 20 & & & 2 & 12 & 21 & 64 \\
\hline & & 25 & & & 2 & 3 & 9 & 87 \\
\hline
\end{tabular}

Remarks: The numbers of bond breakings are plotted and compared in Fig. 9.

\subsection{Influence of GAR and $\boldsymbol{n}$ on Young's modulus $\boldsymbol{E}$}

The effect of $\boldsymbol{G A R}$ and porosity $\boldsymbol{n}$ on Young's modulus $\boldsymbol{E}$ is shown in Fig. 8. It can be seen that, under a specific porosity $\boldsymbol{n}$, increasing $\boldsymbol{G A R}$ increases $\boldsymbol{E}$. Since the increase of $\boldsymbol{G A R}$ under a constant $\boldsymbol{n}$, which was modeled by replacing some of matrix particles with grain particles, leads to a greater $\boldsymbol{E}$, this observation suggests the stiffness in between grains is greater than that in between matrix particles.

On the other hand, under a constant $\boldsymbol{G A R}$, a decrease in the porosity $\boldsymbol{n}$ increases the $\boldsymbol{E}$ as shown in Fig. 8. Decreasing porosity means more matrix particles and less porous matrix particles and void and leads to a more consolidated packing of the particles and the matrix. This densely packed structure tends to give larger stiffness than loosely packed structures. Consequently, increased number of particles accounts for the increase in $\boldsymbol{E}$.

The simulation of the influence of $\boldsymbol{G A R}$ and porosity $\boldsymbol{n}$ on the UCS and $\boldsymbol{E}$ enables further validation on the selected parameters for the adopted model. The base set of parameters was selected from a set of $\boldsymbol{G A R}$ and $\boldsymbol{n}$, and simulations were conducted to yield variations of $\boldsymbol{U C S}$ and $\boldsymbol{E}$. The simulated variations are then compared with those of natural sandstones under various $\mathbf{G A R}$ and $\boldsymbol{n}$ as shown in Figs. 7 and 8. Fairly good agreement of the predictions with the actual behaviors shows that the proposed model is acceptable for use in further analyses.

\section{Contact type distribution}

As described in Section 2, the proposed model comprises three types of particles: GP, $\boldsymbol{M P}$, and $\boldsymbol{P P}$; and involves four types of contacts: $\boldsymbol{G}-\mathbf{G}, \boldsymbol{M}-\boldsymbol{M}, \boldsymbol{M}-\boldsymbol{G}$, and $\boldsymbol{P}-\boldsymbol{P}$. In the proposed model, the variations of porosity $\boldsymbol{n}$ and $\boldsymbol{G A R}$ change both the number of particles and the relative number of contacts amongst different contact types, as shown in Table 4 and Fig. 9.

Fig. 9a shows the proportions of four contact types $\boldsymbol{M}-\boldsymbol{M}, \boldsymbol{M}-\mathbf{G}, \mathbf{G}-\mathbf{G}$, and $\boldsymbol{P}-\boldsymbol{P}$ when $\boldsymbol{G A R}$ is 35\%. It is seen in Fig. 9a that, with increase in porosity $\boldsymbol{n}$ from $10 \%$ to $25 \%$, the proportion of $\boldsymbol{P}-\boldsymbol{P}$ significantly increases and the proportions of $\boldsymbol{M}-\boldsymbol{M}$ and $\boldsymbol{M}-\boldsymbol{G}$ contacts correspondingly decrease. The proportion of $\mathbf{G}-\mathbf{G}$ contact remains constant due to its tie to $\boldsymbol{G A R}$. Similar changes to proportions of different contact types can be seen with variation in $\mathbf{G A R}$ in the range of $55 \%$ and $75 \%$ as shown in Fig. 9b and c. Nevertheless, due to the increase of $\boldsymbol{G A R}$, the number of $\boldsymbol{G P}$ particles relatively increases, and the proportion of $\boldsymbol{M}-\boldsymbol{G}$ and $\boldsymbol{G}-\boldsymbol{G}$ contacts increases accordingly. It can also be seen in Fig. 9 that the $\mathbf{G}-\boldsymbol{G}$ contact has a rather low percentage, not exceeding $2 \%$, this rather low percentage of $\boldsymbol{G}-\boldsymbol{G}$ is resulted from the relatively large diameter of the grain particles (GP), when compared to other particle types in the adopted model.

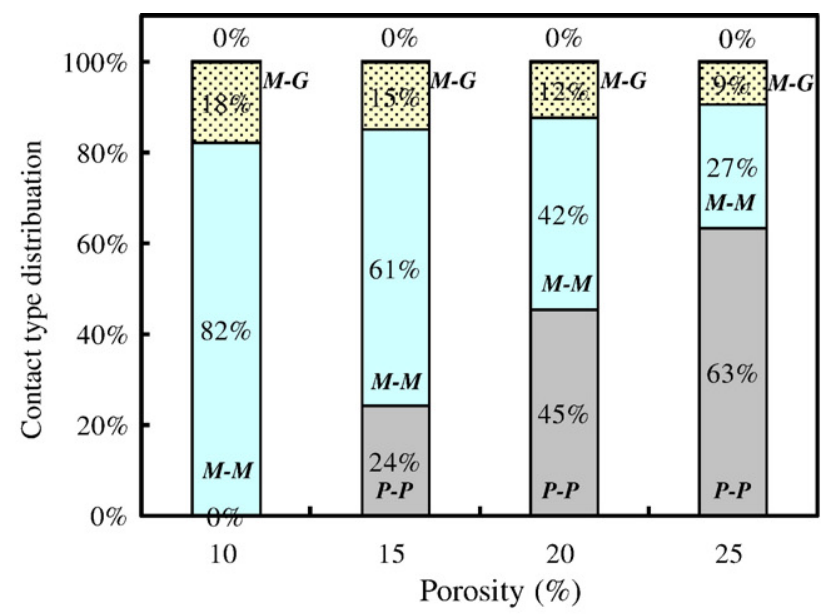

(a) $\boldsymbol{G A R}=35 \%$

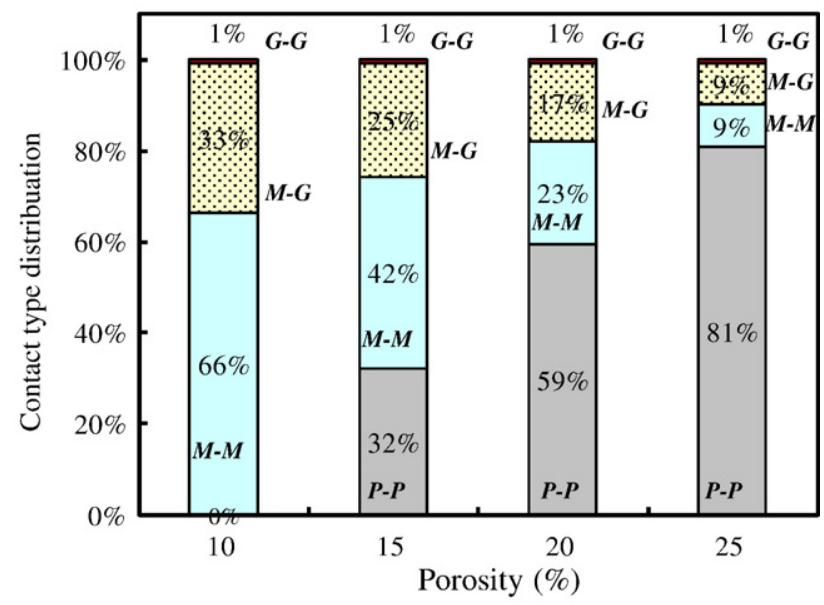

(b) $\boldsymbol{G A R}=55 \%$

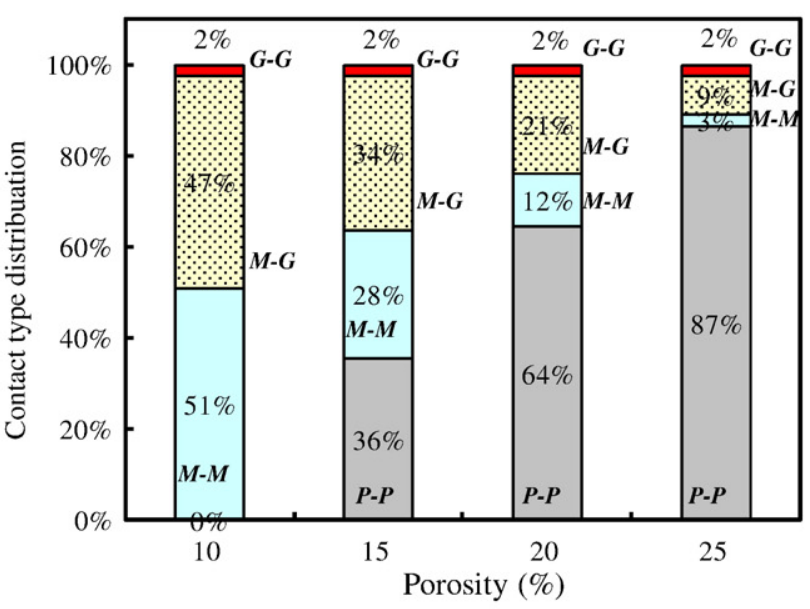

(c) $\boldsymbol{G A R}=75 \%$

$\square P-P \quad \square M-M \quad \square M-G \quad \square G-G$

Fig. 9. Variations of contents of four contact types with porosity $\boldsymbol{n}$ and $\boldsymbol{G A R}$ ranging from $0 \% \sim 25 \%$ and $35 \% \sim 75 \%$, respectively. The numbers of contacts and bond breakings for three cases ( $\boldsymbol{G A R}=35 \%, 55 \%$ and $75 \%$ ) plotted in this figure are summarized in Table 4 . 


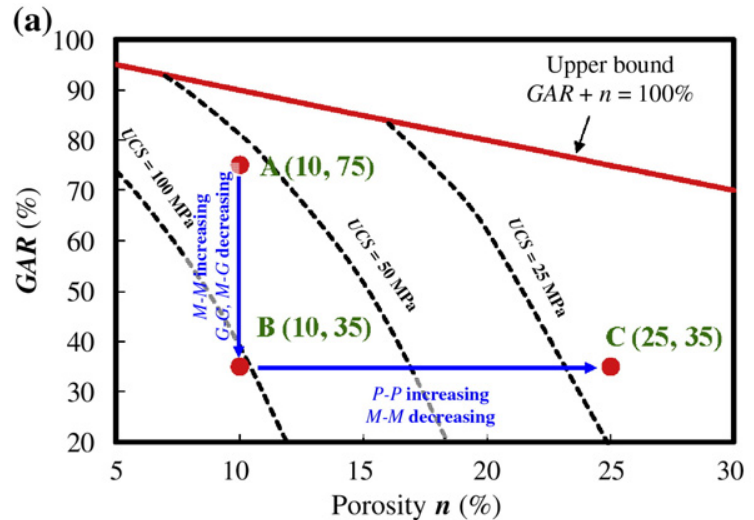

(b)

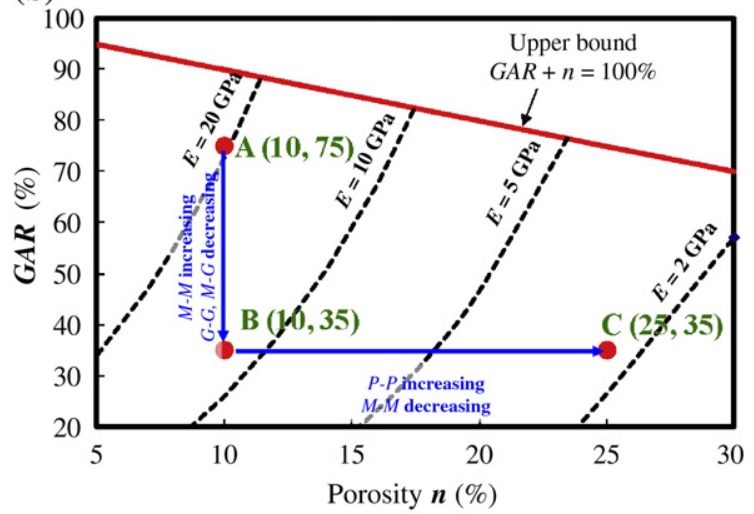

Fig. 10. Variations of $\boldsymbol{U C S}$ and $\boldsymbol{E}$ corresponding to the $\boldsymbol{G A R}$ and $\boldsymbol{n}$ of Cases A, B and C.

The observation on the changes in the proportion of different contact types and the failure of bonding provides us a sound basis to explore the micro-mechanism behind the macroscopic mechanical of sandstones, concerning the dominant contact type affecting the UCS under various combination of porosity $\boldsymbol{n}$ and $\boldsymbol{G A R}$, especially.

Fig. 10a and b shows contours of $\boldsymbol{U C S}$ and $\boldsymbol{E}$ respectively under various combination of porosity $\boldsymbol{n}$ and $\boldsymbol{G A R}$, which are based on the actual behavior of natural sandstone (Jeng et al., 2004). Three cases of macroscopic failure, referred to as Cases $A, B$, and $C$, are discussed in the following. The corresponding bonding failure types when approaching particle failure for the three cases are summarized in Table 5.

In transitioning from Case A to Case B, in which GAR decreases under constant porosity, e.g. $\boldsymbol{U C S}$ increases and Young's modulus $\boldsymbol{E}$ decreases, as shown in Fig. 10. Meanwhile, the major type of broken bonding transit from $\boldsymbol{M}-\boldsymbol{G}$ and $\boldsymbol{G}-\boldsymbol{G}$ dominant to $\boldsymbol{M}-\boldsymbol{G}$ and $\boldsymbol{M}-\boldsymbol{M}$ dominant, as shown in Table 5.

This phenomenon is readily interpreted by the fact that a decrease of $\boldsymbol{G A R}$ reduces the number of $\boldsymbol{G P}$ and increases the number of $\boldsymbol{M P}$. As

Table 5

Summation of the number of cracks yielded by Cases $A, B$ and $C$

\begin{tabular}{|c|c|c|c|}
\hline \multirow{3}{*}{ Contact type } & Case A & Case B & Case C \\
\hline & $n=10 \%$ & $n=10 \%$ & $n=10 \%$ \\
\hline & $G A R=75 \%$ & $G A R=35 \%$ & $G A R=75 \%$ \\
\hline$\overline{P-P}$ & $0 \%$ & $0 \%$ & $55 \%$ \\
\hline$M-M$ & $0 \%$ & $22 \%$ & $1 \%$ \\
\hline$M-G$ & $76 \%$ & $75 \%$ & $41 \%$ \\
\hline$G-G$ & $24 \%$ & $3 \%$ & $3 \%$ \\
\hline Total number of cracks & 225 & 673 & 272 \\
\hline
\end{tabular}

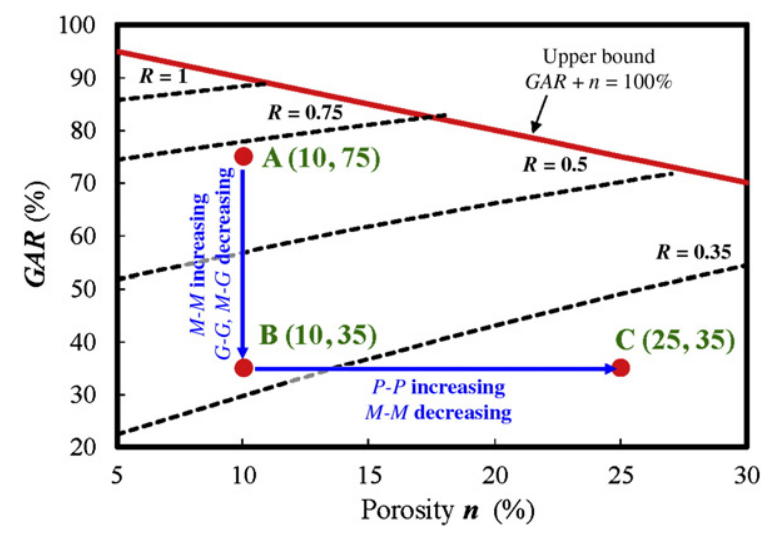

Fig. 11. Variations of $\boldsymbol{R}$ corresponding to the $\boldsymbol{G A R}$ and $\boldsymbol{n}$ of Cases $A, B$ and $C$.

the number of $\boldsymbol{G P}$ decreases, the number of $\boldsymbol{M}-\boldsymbol{G}$ bonding decreases; as the number of $\boldsymbol{M P}$ increases, the number of $\boldsymbol{M}-\boldsymbol{M}$ bonding increases. For the $\boldsymbol{M}-\boldsymbol{M}$ bonding, its strength is higher than $\boldsymbol{M}-\boldsymbol{G}$ bonds and its stiffness is lower than $\boldsymbol{M}-\boldsymbol{G}$ bonds, thus the macroscopic strength $\boldsymbol{U C S}$ increases in Fig. 10a from Case A to Case B; macroscopic Young's modulus $\boldsymbol{E}$ decreases from Case $A$ to Case $B$ in Fig. 10b.

When transitioning from Case $B$ to Case $C$, with porosity increasing from $10 \%$ to $25 \%$ under a constant GAR of 35\%, as shown in Fig. 10a and b, both macroscopic $\boldsymbol{U C S}$ and $\boldsymbol{E}$ decrease.

For Case C, due to the increase of porosity under a constant $\mathbf{G A R}$, parts of $\boldsymbol{M P s}$ are replaced by $\boldsymbol{P P}$ such that the number of $\boldsymbol{P}-\boldsymbol{P}$ increases and the number of $\boldsymbol{M}-\boldsymbol{M}$ bond decreases in the meanwhile. As a result, the most failed bonds are $\boldsymbol{P}-\boldsymbol{P}$ and $\boldsymbol{M}-\boldsymbol{G}$ bonds. The $\boldsymbol{P}-\boldsymbol{P}$ bond features relatively lower strength and stiffness, and therefore the more $\boldsymbol{P}-\boldsymbol{P}$ bonds leads to reductions of the macroscopic $\boldsymbol{U C S}$ and $\boldsymbol{E}$ as well.

\section{Influence of bonding strength on the wet-softening behavior of sandstone}

The wet-softening behavior of sandstones refers to the reduction of shear strength when the material is wetted by water. This wetsoftening behavior is owing to the fact that the bonding strength of matrix materials is reduced when the sandstone is wetted (Dobereiner and De Freitas, 1986; Lin et al., 2005). The degree of UCS reduction can be expressed in $\boldsymbol{R}$, a measure of the so-called strength reduction ratio defined as the ratio of the $\boldsymbol{U} \boldsymbol{C S}$ of dry rock by the $\boldsymbol{U} \boldsymbol{C S}$ of wet rock (Jeng et al., 2004; Weng et al., 2005). The relationship, proposed by Jeng et al. (2004), between $\boldsymbol{R}$ and porosity $\boldsymbol{n}$ and $\boldsymbol{G A R}$ is shown in Fig. 11. Under low porosity $\boldsymbol{n}$ and high $\mathbf{G A R}$, there is little matrix content, thus $\boldsymbol{R}$ is close to unity and indicates little reduction of strength when soaked; on the contrary, with high porosity $\boldsymbol{n}$ and low $\boldsymbol{G A R}$, the matrix content is high, $\boldsymbol{R}$ is close to 0 and represents significant wet-softening behavior.

Through mechanical regression analyses between laboratory experiments and thin-slice observations, the relationship between $\boldsymbol{R}$ and porosity $\boldsymbol{n}$ and $\boldsymbol{G A R}$ can be established. However, the influence of bonding on macroscopic strength is difficult to study using the abovementioned conventional methods. The proposed model offers a way to explore the effect of particle bonding on macroscopic mechanical behaviors.

Fig. 12 shows the effect of bonding strength of each individual bonding type on the macroscopic UCS for Cases A, B, and C. In Fig. 12, all the bonding strengths are normalized with respect to the corresponding dry strengths of Cases $A, B$, and $C$ respectively. For Case $A$, as shown in Fig. 12a, with $10 \%$ of porosity and $75 \%$ of $\boldsymbol{G A R}$, the reduction of $\boldsymbol{M}-\boldsymbol{G}$ bond most significantly decreases the macroscopic UCS. Whereas, reductions of $\boldsymbol{M}-\boldsymbol{M}$ and $\boldsymbol{G}-\boldsymbol{G}$ bonding strength result 


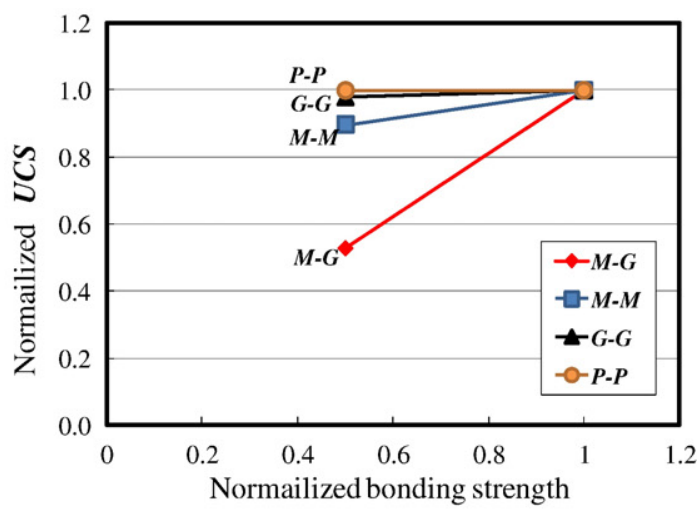

(a) Case A $(\boldsymbol{n}=10 \%, \boldsymbol{G A R}=75 \%)$

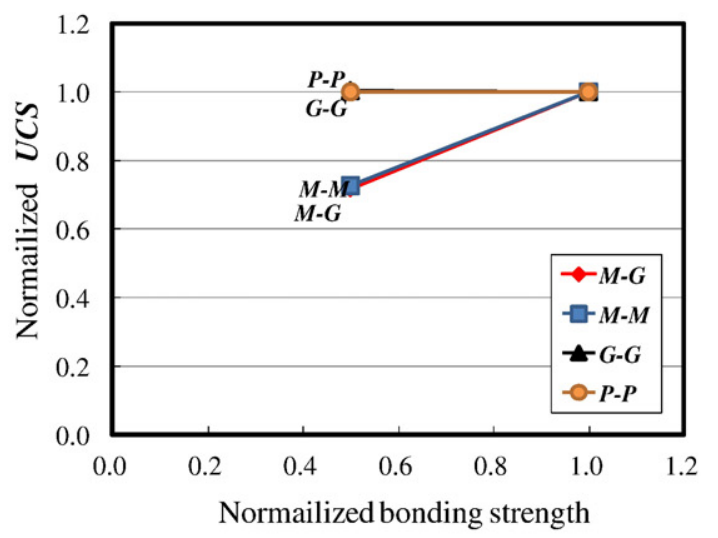

(b) Case B $(\boldsymbol{n}=10 \%, \boldsymbol{G A R}=35 \%)$

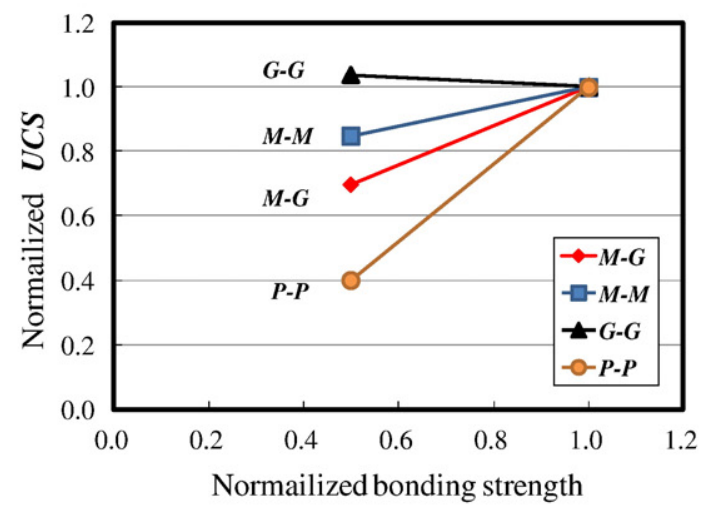

(c) Case C $(\boldsymbol{n}=25 \%, \boldsymbol{G A R}=35 \%)$

Fig. 12. Variation of $\boldsymbol{U C S}$ upon varying bonding strengths of contacts.

in a moderate $\boldsymbol{U C S}$ reduction and $\boldsymbol{P}-\boldsymbol{P}$ bonding has little effect on UCS.

For a lower $\mathbf{G A R}$ under a constant porosity, such as Case B with $10 \%$ of porosity and 35\% of $\boldsymbol{G A R}$, reduction of $\boldsymbol{M}-\boldsymbol{G}$ and $\boldsymbol{M}-\boldsymbol{M}$ bonding strength leads to significant reduction of $\boldsymbol{U C S}$, and the strength reduction of $\boldsymbol{G}-\boldsymbol{G}$ and $\boldsymbol{P}-\boldsymbol{P}$ bonding have an insignificant effect on $\boldsymbol{U C S}$ (Fig. 12b).

Fig. 12 c depicts, Case $C$ with $25 \%$ of porosity and $35 \%$ of $\mathbf{G A R}, \boldsymbol{P}-\boldsymbol{P}$ bonding strength reduction renders significant reduction of $\mathbf{U C S}, \boldsymbol{M}$ $\boldsymbol{M}, \boldsymbol{M}-\boldsymbol{G}$, and $\boldsymbol{G}-\boldsymbol{G}$ bonding strength reductions have lesser and lesser effect on $\boldsymbol{U C S}$ reduction.
On one hand, the global GAR or porosity $\boldsymbol{n}$ determines the numbers of each contact type. In turn, the specific distribution of the contact types, the three cases studied for instance, dominates not only UCS and $\boldsymbol{E}$ but also the degree of wet softening of sandstone $\boldsymbol{R}$.

\section{Conclusion}

In this study, how the microscopic factors, e.g. particle types and the corresponding bonding strength and stiffness, affect the macroscopic $\boldsymbol{U C S}, \boldsymbol{E}$ and $\boldsymbol{R}$ of sandstones was explored.

A model based on bonded-particle method was proposed to simulate the macroscopic mechanical behaviors of sandstones. The proposed numerical model contained three types of particles: grain particles $(\boldsymbol{G P})$, matrix particles $(\boldsymbol{M P})$, and porous matrix particles $(\boldsymbol{P P})$. These two additional types of particles introduced in this study, MP and $\boldsymbol{P P}$, greatly facilitated the study on the effects of petrographic parameters $\boldsymbol{G A R}$ and porosity $\boldsymbol{n}$ on the macroscopic mechanical behaviors. The model had been verified for modeling sandstones and showed good capability in simulating/predicting the macroscopic mechanical behavior of sandstones. Meanwhile, the porosity was taken into consideration, and porous matrix particles were introduced. These particles enabled simulations with a wide range of porosity, from $10 \%$ to $25 \%$, and facilitated the corresponding observation on the variations of $\boldsymbol{U C S}$ and Young's modulus $\boldsymbol{E}$ with varying porosity.

Overall, this study revealed reasonable explanations on why the $\boldsymbol{U C S}$ and $\boldsymbol{R}$ vary according to $\boldsymbol{G A R}$ and porosity $\boldsymbol{n}$ as follows:

(1) As long as the $\boldsymbol{M}-\boldsymbol{M}$ bond is stronger than $\boldsymbol{G}-\boldsymbol{G}$ bond, a decrease in $\boldsymbol{G A R}$ will lead to the increase of $\boldsymbol{U C S}$ in the macroscopic manner under a constant porosity (Fig. 10a);

(2) On the other hand, provided that $\boldsymbol{M}-\boldsymbol{M}$ bond is softer than $\boldsymbol{G}-\boldsymbol{G}$ or $\boldsymbol{M}-\boldsymbol{G}$ bonds and under a constant porosity, a decrease in $\boldsymbol{G A R}$ will lead to the decrease of $\boldsymbol{E}$ under a constant porosity (Fig. 10b).

(3) An increase in $\boldsymbol{P}-\boldsymbol{P}$ bonds leads to reductions of $\boldsymbol{U C S}$ and $\boldsymbol{E}$ (Change from Case B to Case C, shown in Fig. 10); and

(4) When a sandstone possesses a greater number of $\boldsymbol{P}-\boldsymbol{P}$ bonds or $\boldsymbol{M}-\boldsymbol{M}$ bonds, this sandstone tends to have a greater wetting reduction of $\boldsymbol{U C S}$, as shown in Figs. 11 and 12.

Given the methodology and the results presented in previous sections, this research has its limitations and further researches are of interest:

(1) The analysis in this study is 2-dimensional, and the true geometrical condition of specimens in unconfined uniaxial compression tests cannot be fully represented. Three-dimensional analyses are inherently more representative of the threedimensional nature of rock and can be used to further check the validity of this work.

(2) The void ratio is $10 \%$; however, other types of rocks may have much lower void ratio. Reduction of void ratio means more particles in the computer model are needed, which may not be feasible using standard single-processor computers.

(3) The types of grains considered are mainly based on sedimentary rocks. Such types of grains may not represent other rock types (including igneous rocks, metamorphic rocks and others). More studies should be carried out to find adequate models for different rock types.

(4) The type of grain contacts considered is point contact. As such, the influence of grain-contact types on the macroscopic behavior awaits to be further studied. More simulation techniques should be developed to represent other types of rocks.

(5) The used of porous particle facilitates simulation of natural sandstone; however, it does pose limitations. The stiffness and bonding strength are determined based on back analyses, 
which are not physical properties than can be obtained through laboratory experiments since the "porous matrix" is a conceptual model rather than an actual material.

\section{Acknowledgments}

The research is partly supported by the National Science Council of Taiwan, grant numbers NSC-95-2221-E-002-261 and NSC-95-2221-E002-263. Authors thank Mr. Christopher Fong for his help and advices in improving the paper.

\section{References}

Barbour, T.G., Atkinson, R.H., Ko, H.Y., 1979. Relationship of Mechanical Index and Mineralogic Properties of Coal Measure Rock: 20th Symposium of Rock Mechanics, Austin, Texas, pp. 189-198.

Bell, F.G., 1978. Physical and mechanical properties of the fell sandstones, Northumberland, England. Engineering Geology 12 (1), 1-29.

Bell, F.G., Culshaw, M.G., 1993. A survey of the geotechnical properties of some relatively weak Triassic sandstones. The Engineering Geology of Weak Rock: Proceedings of the 26th Annual Conference of the Engineering Group of the Geological Society, Leeds, United Kingdom. Balkema, Rotterdam, pp. 139-148.

Bell, F.G., Culshaw, M.G., 1998. Petrographic and engineering properties of sandstones from the Sneinton Formation, Nottinghamshire, England. Quarterly Journal of Engineering Geology 31, 5-19.

Clough, G.W., Sitar, N., Bachus, R.C., 1981. Cemented sands under static loading. Journal of Geotechanical Engineering Division 107 (6), 799-817.

Cho, N., Martin, C.D., Sego, D.C., 2007. A clumped particle model for rock. International Journal of Rock Mechanics and Mining Sciences 44, 997-1010.

David, C., Menendez, B., Bernabe, Y., 1998. The mechanical behaviour of synthetic sandstones with varying brittle cement content. International Journal of Rock Mechanics and Mining Sciences 35 (6), 759-770.

Dobereiner, L., De Freitas, M.H., 1986. Geotechnical properties of weak sandstone. Geotechnique 36 (1), 79-94.

Dyke, C.G., Dobereiner, L., 1991. Evaluating the strength and deformability of sandstones. Quarterly Journal of Engineering Geology 24, 123-134.

Ersoy, A., Waller, M.D., 1995. Textural characterisation pf rock. Engineering Geology 39, $123-136$.

Gunsallus, K.L., Kulhaway, F.H., 1984. Comparative evaluation of rock strength measurements. International Journal Rock Mechanics and Mining Sciences \& Geomechanics Abstracts 21 (5), 233-248.

Hatzor, Y.H., Plachik, V., 1997. The influence of grain size and porosity on crack initiation stress and critical flaw length in dolomites. International Journal of Rock Mechanics and Mining Sciences 34 (4), 805-816.

Hatzor, Y.H., Plachik, V., 1998. A microstructure-based failure criterion for Aminadav dolomites. International Journal of Rock Mechanics and Mining Sciences 35 (6), 797-805.
Hawkins, A.B., McConnell, B.J., 1992. Sensitivity of sandstone strength and deformability to changes in moisture content. Quarterly Journal of Engineering Geology 25, $115-130$.

ISRM, 1981. In: Brown, E.T. (Ed.), Rock Characterization, Testing and Monitoring-ISRM Suggested Methods. Pergamon, New York. 211 pp.

Iverson, S.R., 2003. Investigation of bulk solids engineering properties and application of PFC2D to ore pass flow problems. In: Konietzky, H. (Ed.), Numerical Modeling in Micromechanics via Particle Methods. Proceedings of the 1st International PFC Symposium, Gelsenkirchen, Germany. Balkema, Rotterdam, pp. 252-258. Netherlands.

Jeng, F.S., Ju, G.T., Huang, T.H., 1994. Properties of Some Weak Rock in Taiwan: Proceedings of The 1994 Taiwan Rock Engineering Symposium. National Central University, Chungli, Taiwan, pp. 259-267.

Jeng, F.S., Weng, W.C., Huang, T.H., Lin, M.L., 2002. Deformational characteristics of weak sandstone and impact to tunnel deformation. Tunnelling and Underground Space Technology 17, 263-264.

Jeng, F.S., Weng, M.C., Lin, M.L., Huang, T.H., 2004. Influence of petrographic parameters on geotechnical properties of Tertiary sandstones from Taiwan. Engineering Geology 73, 71-91.

Lin, M.L., Jeng, F.S., Tsai, L.S., Huang, T.H., 2005. Wetting weakening of tertiary sandstones-microscopic mechanism. Environmental Geology 48, 265-275.

Shakoor, A., Bonelli, R.E., 1991. Relationship between petrographic characteristics, engineering index properties, and mechanical properties of selected sandstone. Bulletin of the Association of Engineering Geologists 28, 55-71.

Singh, S.K., 1988. Relationship among fatigue strength, mean grain size and compressive strength of a rock. Rock Mechanics and Rock Engineering 21, 271-276.

Smart, B.D., Rowlands, N., Isaac, A.K., 1982. Progress towards establishing relationships between the mineralogy and physical properties of coal measures rocks International Journal of Rock Mechanics and Mining Sciences \& Geomechanics Abstracts 19, 81-89.

Tsai, L.S., Hsieh, Y.M., Weng, M.C., Huang, T.H., Jeng, F.S., 2008. Time-dependent Deformation Behaviors of Weak Sandstones. International Journal Rock Mechanics and Mining Sciences 45, 144-154.

PFC2D (Particle Flow Code in 2 Dimension) Version 3.1, 2004. Itasca Cons Group, Minneapolis.

Plachik, V., 1999. Influence of porosity and elastic modulus on uniaxial compressive strength in soft brittle porous sandstones. Rock Mechanics and Rock Engineering 32, 303-309.

Potyondy, D.O., Cundall, P.A., 2004. A bonded-particle model for rock. International Journal of Rock Mechanics and Mining Sciences 41,1329-1364.

Ulusay, R., Tureli, K., Ider, M.H., 1994. Prediction of engineering properties of selected litharenite sandstone from its petrographic characteristics using correlation and multivariate statistical techniques. Engineering Geology 37, 135-157.

Vutukuri, V.S., Lama, R.D., Saluja, S.S., 1974. Handbook on Mechanical Properties of Rocks.

Weng, M.C., Jeng, F.S., Huang, T.H., Lin, M.L., 2005. Characterizing the deformation behavior of tertiary sandstones. International Journal of Rock Mechanics and Mining Sciences 42, 388-401.

Weng, M.C., Jeng, F.S., Hsieh, T.M., Huang, T.H., 2008. A simple model for stress-induced anisotropic softening of weak sandstones. International Journal of Rock Mechanics and Mining Sciences 45, 155-166. 